\title{
COVID-19 Pandemic: A Global Health Development Point of View
}

\author{
Faisal Muhammad (iD ${ }^{1,2, *}$ \\ ${ }^{1}$ Department of Public Health, Faculty of Allied Health Sciences, Daffodil International University, Dhaka, Bangladesh \\ ${ }^{2}$ Department of Social Work, School of Liberal Arts and Social Sciences, University of Information Technology and Sciences, Dhaka, Bangladesh \\ "Corresponding author: Department of Public Health, Faculty of Allied Health Sciences, Daffodil International University, Mirpur Road Dhanmondi, Dhaka, Bangladesh. Email: \\ fokkanya@yahoo.com
}

Received 2020 April 29; Revised 2020 May 13; Accepted 2020 May 14.

Keywords: COVID-19, Pandemic, Global Health, Infectious Diseases

\section{Dear Editor,}

The novel coronavirus diseases (COVID-19) pandemic has created a lot of disruptions to the global health development. The short-term consequences of this global pandemic are known; however, the long-term consequences are difficult to be predicted. Currently, most countries lack enough equipment to fight against COVID-19. Nevertheless, some countries have tried drastically to produce the required materials and equipment domestically (such as equipment, pharmaceutical agents, and medical supplies). As a result of COVID-19 pandemic, the world realized the economic costs of a pandemic outbreak; thus, this experience will lead to more investment in research and prevention. Through this outbreak, we learn how close to each other our world is in terms of vulnerability (1). The COVID19 has spread all over the world and causes shutting down most of the countries across the globe. Most of pre-COVID19 operations going on are monitored and carried out by domestic state institutions; hence, this is the important aspect of global health governance (2).

The COVID-19 pandemic hopefully will alter the global health community's acceptance and use of digital health technologies nowadays since the global health systems are overwhelmed as a result of responding to the COVID-19 pandemic. Most healthcare providers turn to telemedicine to reduce exposure to COVID-19 as well as discovered the effectiveness of telehealth. Hopefully, these modern technologies are expected to be the means that will help the healthcare providers to get closer to each other in order to share the goal of universal health coverage. The COVID-19 pandemic has put greater value on research and epidemiological investigations all over the world (1). As a result of the COVID-19 pandemic outbreak, the concerned author- ity will somehow force a reexamination of global health architecture. I have no doubt the governments are going to promote an approach to sustainability and increase investment in health research, emergency preparedness, and strengthen the overall healthcare systems.

\section{Footnotes}

Authors' Contribution: All the work was done by Faisal Muhammad.

Conflict of Interests: The author has no conflict of interest.

Funding/Support: None declared.

\section{References}

1. Igoe M, Chadwick V. After the pandemic: How will COVID-19 transform global health and development? 2020, [cited 2020 Apr 16]. Available from: www.devex.com/news/after-the-pandemic-how-will-covid19-transform-global-health-and-development-96936.

2. Hameiri S. Covid-19: Why did global health governance fail? Despite the existence of a "World Health Organization" very limited collective capacity had developed previously. 2020, [cited 2020 Apr 16]. Available from: www.lowyinstitute.org/the-interpreter/covid-19-whydid-global-health-governance-fail. 